\title{
English rural policing: job stress and psychological distress
}

English rural policing

\author{
Jonathan Houdmont \\ School of Medicine, University of Nottingham, Nottingham, UK \\ Liza Jachens \\ Department of Psychology, Webster University - Geneva Campus, \\ Geneva, Switzerland \\ Raymond Randall \\ Institute for Work Psychology, Sheffield University Management School, \\ The University of Sheffield, Sheffield, UK, and \\ Jim Colwell \\ Devon and Cornwall Constabulary, Exeter, UK
}

\begin{abstract}
Purpose - Job stressor exposure is associated with mental health in police officers. Police stress research rarely draws a distinction between urban and rural policing, raising the possibility that stressors specific to the rural context remain unidentified and their implications unknown. This may hinder actions to protect the mental health of those involved in policing rural communities.

Design/methodology/approach - Among rural policing teams in an English county police force this study used an exploratory sequential mixed method design to (1) identify and quantify exposure to rural policing stressors and (2) examine links between job stressor exposure and psychological distress.

Findings - Interviews $(N=34)$ identified three rural policing job stressor themes: (1) job demands, (2) isolation and (3) critical decisions. Survey data $(N=229)$ indicated significant differences in exposure by rank to demand and critical decision stressors, with police community support officers (PCSOs) reporting lower exposure than officers of constable and sergeant rank. Overall, $44 \%$ of respondents reported symptoms of psychological distress indicative of likely minor psychiatric disorder; higher levels of psychological distress were associated with higher stressor exposure across all three job stressor themes for PCSOs and constables and within the job demand theme for sergeants.
\end{abstract}

Originality/value - Findings point towards practical actions focussed on resource provision for officers and a research strategy to ameliorate the impact of stressors in English rural policing.

Keywords GHQ-12, Job stress, Police, Psychological distress, Rural

Paper type Research paper

\section{Introduction}

A 2018 survey of 18,000 police officers across England and Wales found a prevalence rate for high job stressfulness three times that of the British adult working population, with one-quarter having sought help in the preceding year for feelings of stress or other mental health and wellbeing difficulties (Elliott-Davies, 2018). Consistent with this, more than half of 1,226 English officers surveyed in 2014-2015 reported symptoms of psychological distress

(C) Jonathan Houdmont, Liza Jachens, Raymond Randall and Jim Colwell. Published by Emerald Publishing Limited. This article is published under the Creative Commons Attribution (CC BY 4.0) licence. Anyone may reproduce, distribute, translate and create derivative works of this article (for both commercial and non-commercial purposes), subject to full attribution to the original publication and authors. The full terms of this licence may be seen at http://creativecommons.org/licences/by/4.0/ legalcode

Funding: Jonathan Houdmont received funding for this study from Devon and Cornwall Police and Devon and Cornwall Police Federation.

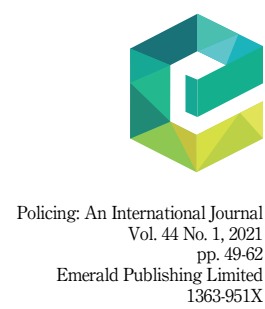

Received 5 March 2020 Revised 1 October 2020 Accepted 2 October 2020 
PIJPSM

44,1 over the previous few weeks indicative of likely minor psychiatric disorder (Houdmont and Randall, 2016), while a similar proportion of frontline patrol constables surveyed in 2017 reported high burnout, four out of five high perceived stress, two-thirds had experienced a mental health problem and $88 \%$ felt that their job had a negative impact on their mental health (Sheard et al., 2019).

Mental health problems in policing are inversely and strongly linked to rank: data from 20 police forces across the United Kingdom (UK) revealed that over the ten year period to 2018, $46 \%$ of sickness absence due to "psychological illness or stress" was within the constable rank, with sergeants accounting for $7 \%$ and those of inspector or higher ranks $2 \%$ (and the remainder accounted for by civilian staff). Overall, $56 \%$ of these absences were ascribed to stress (Cartwright and Roach, 2020). A similar relationship has been observed in UK policing between job stressor exposures and rank, with those in the lower ranks reporting poorer job control, communication and consultation about change and managerial support and more role ambiguity (Houdmont et al., 2012). In the current study, we consider frontline members of English rural policing teams with a focus on the role of constable - the first rank after an officer is sworn in - and sergeant - the first supervisory rank. In 2019, there were 96,070 constables and 18,460 sergeant across England and Wales (Home Office Statistics, 2019). Our analyses also encompass a role largely neglected by stress researchers, but which is nevertheless important within rural policing teams, that of police community support officer (PCSO). The PCSO is a uniformed member of police staff typically involved in neighbourhood policing whose job entails carrying out highly visible patrols, resolving community problems, gathering intelligence, dealing with anti-social behaviour and crime scene preservation. Often the first uniformed presence at an incident, PCSOs do not have the same powers of arrest as sworn officers and owing to the nature of the role generally do not carry batons or handcuffs. In 2019, there were 9,547 PCSOs across England and Wales (Home Office Statistics, 2019).

In recent years, job demands-resources (JD-R) theory (Bakker and Demerouti, 2017) has become a widely used framework for the examination of job stress across occupations, including policing (e.g. Raper et al., 2020). JD-R theory posits that all work characteristics can be classified as demands or resources, the former being "those physical, psychological, social, or organizational aspects of the job that require sustained physical and/or psychological effort" (Bakker and Demerouti, 2017, p. 274). Sustained exposure to job demands instigates a health impairment process resulting in negative outcomes for individuals (e.g. mental ill-health) and their organizations (e.g. absence). In contrast, job and personal resources stimulate a motivational process resulting in high work engagement and positive performance outcomes, while also buffering the health impairment process. This study conceptualizes job demands as aspects of work that police officers perceive to present a threat to their mental well-being.

Job stress research in English policing has tended to consider officers as a homogenous group and use generic job stressor measures that are designed for application across occupations (e.g. Allisey et al., 2014). However, given the diversity of policing roles and contexts, there is a need for research that recognizes heterogeneity and assesses context- and role-specific stressors. Such research could inform the design and targeting of stress reduction interventions tailored to specific groups. In recent times there have been developments in this regard with English and Welsh police stress studies having explored the context- and role-specific stressors of custody officers (Houdmont, 2013), detectives (Boag-Munroe, 2017) and child sexual abuse investigators (Hurrell et al., 2018). The current study offers a contribution to the literature on context-specific job stress by focussing on the policing of rural communities in England.

Rural crime has distinctive characteristics that are reflected in the operational rural affairs priorities for UK police forces. These focus on farm machinery, plant and vehicle theft; livestock offences; fuel theft; equine crime; fly tipping (illegal dumping of waste) and 
poaching (National Police Chiefs' Council, 2018). Beyond these foci, the most prevalent types of crime in rural communities mirror those experienced in urban areas: a survey of 17,000 rural workers and residents in England, Wales, and Northern Ireland identified burglary (17.5\% of crimes), arson/vandalism/criminal damage $(16.6 \%)$ and harassment $(10.4 \%)$ as the three most commonly experienced forms of crime (National Rural Crime Network, 2015). Results further demonstrated low levels of satisfaction with the police in rural communities, with 39\% agreeing that the police can be relied upon to be present when needed, compared to $61 \%$ nationally. Moreover, $39 \%$ reported being very or fairly worried about being a victim of crime compared to $19 \%$ nationally, and $32 \%$ were more fearful of being a victim of crime than they were five years ago. Similar findings were observed in a study of residents in the county of Cornwall - where the current study was conducted - which found that community perceptions of the police in rural areas were poorer than in urban areas, with unease over public safety exacerbated by concerns about rural officers being less accessible than their urban counterparts (Mawby, 2009). Recent increases in rural crime are ascribed to social and economic change that has seen farm closures and the break-up of close-knit communities alongside improved transport links that allow for the efficient movement of stolen machinery to mainland Europe (National Farmers' Union, 2017). The total cost of rural crime is estimated to be in excess of $£ 800 \mathrm{~m}(\sim \$ 1 \mathrm{bn})$ per annum, equivalent to $£ 200(\sim \$ 250)$ for every rural household (National Rural Crime Network, 2015).

In countries with large rural inhabited areas, researchers have examined the challenges involved in policing these environments and implications for officers' safety and health. In New Zealand, rural policing was identified as having a more stressful impact on officers' private lives than its urban counterpart (Buttle et al., 2010), while Canadian research exploring job stressors experienced by officers serving rural, often indigenous, communities highlighted risks associated with driving, mismatch between desired vs actual organizational role, bureaucracy, understaffing, vulnerability and lack of backup (Huey and Ricciardelli, 2015, 2017; Ricciardelli, 2018; Ricciardelli et al., 2018). In the United States (US), a mix of generic and context-specific job stressors have been identified in rural settings (Oliver and Meier, 2004; Page and Jacobs, 2011). In recent times, several researchers have sought to compare officers serving urban and rural communities in terms of stress-related health problems. Rural officers in China were observed to experience significantly higher levels of somatization (i.e. the experience of psychological distress in the form of somatic symptoms such as pounding heart and chest, faintness or dizziness, headaches, nausea, trouble getting breath and a lump in the throat) than their urban counterparts, a difference explained in part by resource and training deficits in the rural setting (Wu and Wen, 2020). No differences were observed between the two officer groups for anxiety and depression, which the authors explained in terms of cultural constraints on the overt expression of psychological difficulties. In contrast, a comparison of urban and rural police officers in Pakistan found significantly higher levels of stress, depression and stress among urban officers (Husain, 2019).

It is perhaps surprising that rural policing in England has not been viewed as distinct from its urban counterpart and worthy of a dedicated focus in job stress research. $9.3 \mathrm{~m}$ people $-17 \%$ of the population - live in rural areas (Department for Environment, Food, and Rural Affairs, 2018) defined as "smaller towns (less than 10,000 people), villages, hamlets or isolated dwellings" (Office for National Statistics, 2011). Under this definition, rural areas make up 85\% of England's total land area (Office for National Statistics, 2011). The disparity between the proportion of the population living in a rural area relative to the proportion of rural land mass makes it reasonable to expect that policing rural communities will involve specific and possibly unique challenges, some of which may have implications for officers' mental health. Initial research involving officers serving English rural communities has identified context-specific stressors such as radio signal problems and lack of access to
English rural policing 
PIJPSM 44,1

well-being support provision that is perceived to be the preserve of those based in the vicinity of the force headquarters, suggesting a need for a strand of police stress research focussed on the English rural setting (Jackman et al., 2020).

\section{Aims of the study}

Widespread recognition of the challenge to mental health in policing has stimulated the development of national policy initiatives including the College of Policing's Oscar Kilo online resource (https://oscarkilo.org.uk) and the UK government's investment in the National Police Wellbeing Service (https://oscarkilo.org.uk/national-police-wellbeing-service/). It has also placed a spotlight on the imperative to identify and manage job stressors that may influence officers' mental health. This study was conducted to provide a stimulus for practical actions to ameliorate the impact of job stressors in English rural policing. To that end, there were three specific aims:

(1) Identify characteristics of rural policing perceived by officers to present a threat to mental well-being (job stressors).

(2) Quantify rural policing job stressor exposure, global job stressfulness and psychological distress.

(3) Examine relations between exposure to rural policing job stressors, global job stressfulness and psychological distress.

\section{Method \\ Study context}

This study focussed on the geographical region policed by the Devon and Cornwall Constabulary. This area is predominantly rural. Three of the 12 districts have a population that is $100 \%$ rural, six are classified as "mainly rural" ( $\geq 80 \%$ rural population), while the remaining three are "largely rural" (50-79\% rural population) (Department for Environment, Food, and Rural Affairs, 2014).

\section{Research design}

An exploratory sequential mixed methods design was used. A qualitative phase of data collection using semi-structured interviews with officers drawn from rural policing teams was conducted to identify job stressors germane to rural policing (Aim 1). The identified themes informed the design of a survey instrument that was administered to all uniformed officers within the force's rural policing population to quantify exposure to job stressors identified in the qualitative phase and assess global job stressfulness and psychological distress (Aims 2-3). Ethical approval was obtained from the Faculty of Medicine and Health Sciences Research Ethics Committee at the University of Nottingham (ref: 44-1807).

\section{Method: interviews}

Participants and procedure. 34 police officers drawn from rural policing teams across the predominantly rural Cornwall and Isles of Scilly and Devon basic command units were interviewed by LJ over a two-week period in September 2018. The Police Federation informed its representative in selected stations of when the researcher would visit and tasked them with identifying officers willing to be interviewed and securing a quiet room for interviews. Stations were selected on the basis of geographical dispersion and accessibility in respect to the imperative to cover the rural jurisdiction within the available timeframe. The number of interviews conducted was dictated by two factors. The first was pragmatic: the aim was to 
conduct as many interviews as possible within the available time period, taking into account interviewee availability and distance between rural stations. The second was scientific. To identify common themes across the participant sample interviews continued to the point of thematic saturation whereby additional interviews add little or no new information.

A qualitative semi-structured interview format was used in which an identical set of questions is presented in a fixed sequence to each participant while allowing the researcher to be flexible in exploring relevant issues raised by interviewees. The semi-structured discussion guide permitted exploration of the lived experience of officers and has previously proven efficacious in UK police stress research (Jackman et al., 2020; Turner and Jenkins, 2019). Participants were asked to identify job stressors by considering characteristics of rural policing perceived to present a threat to their mental wellbeing. Interviews lasted for an average of $31 \mathrm{~min}$ and ranged from 15 to $54 \mathrm{~min}$. With the consent of participants interviews were recorded and transcribed verbatim.

Analytical approach. To identify common job stressors in the transcripts in a replicable and transparent manner, guidelines for thematic analysis were applied (Braun and Clarke, 2006). This "method for identifying, analysing and reporting patterns (themes) within data" (Braun and Clarke, 2006, p. 79) is frequently used in police job stressor identification studies (e.g. Demou et al., 2020; Jackman et al., 2020). Deductive and inductive approaches were taken to identify themes, meaning that a set of pre-determined (deductive) themes was applied that was informed by the scientific literature and organizational concerns while remaining open to the emergence of new unexpected (inductive) themes. The focus of analysis was on recurrent themes and sub-themes, i.e. issues that were pertinent to multiple interviewees. The analysis began with initial immersion in the data; $\mathrm{JH}$ read each transcript several times to establish familiarity with the data and noted job stressors that might be of potential interest. A process of coding followed whereby the entire dataset was searched for words or phrases that reflected job stressors experienced by officers. LJ coded a subset of transcripts and codes were compared, with any disagreements discussed before a decision was made. From these codes subsequent candidate themes were developed, i.e. broad organizing concepts that unified codes which recurred in the data and had meaning in relation to the research question. Next, candidate themes and sub-themes were reviewed across transcripts to ensure that they accurately reflected the data, before being defined and named.

\section{Method: survey}

Participants and procedure. All officers within the force's rural policing teams were invited to complete an online survey in January 2019. Eligible officers were made aware of the survey through intranet and email communications that included a hyperlink to the survey and endorsement from a Chief Superintendent (JC). Participation was voluntary and anonymous; participants received written information on the aims of the study and gave their informed consent prior to participation.

Measurement instruments. Exposure to rural policing job stressors was assessed using a set of items that reflected the job stressor themes identified in the preceding interviews. Items pertaining to job demands were drawn from the Management Standards Indicator Tool (Health and Safety Executive, n.d.), while those relating to isolation and decision-making were developed for this study. Respondents indicated frequency of exposure to each job stressor over the last 12 months on a 7-point scale of (1) never, (2) almost never, (3) rarely, (4) sometimes, (5) often, (6) very often and (7) always. A response of often, very often or always indicated high exposure. A mean exposure score was calculated for job demands (6 items, $\alpha=0.80$ ), isolation ( 3 items, $\alpha=0.73$ ), and critical decision making ( 2 items, $\alpha=0.85$ ) themes. We piloted the questionnaire with a small number of police officers to check for errors and
English rural policing 
PIJPSM

44,1

ambiguity and to establish the face validity of the job stressor items, with minor adjustments made in light of feedback.

Global job stressfulness was assessed using a single-item measure with the stem question, "In general, how do you find your job?" and five response options: (1) not at all stressful, (2) mildly stressful, (3) moderately stressful, (4) very stressful and (5) extremely stressful (Smith, 2000). A response of very stressful or extremely stressful indicated high job stress. This single-item measure is widely used in job stress research as an indicator of overall job stressfulness (for a review see Houdmont et al., 2019).

Psychological distress was measured using the 12-item General Health Questionnaire (GHQ-12) (Goldberg and Williams, 1988) that offers a context-free assessment of three dimensions of mental health: anxiety/insomnia, social dysfunction and depression. We used the GHQ scoring method (0-0-1-1) with responses summed to a global score ranging from 0 to 12 and dichotomized into non-distressed (GHQ score $0-3$ ) and distressed (GHQ score $4-12$ ). The $3 / 4$ "caseness" threshold is accurate for identifying likely minor psychiatric morbidity (Aalto et al., 2012).

Analytical approach. Analyses were performed in IBM SPSS V.24 with statistical significance defined as $p<0.05$. For aim 2, Pearson's $\chi^{2}$ tests (with Cramer's $V$ as a measure of effect size) were applied to compare the proportion of respondents reporting high global job stress and psychological distress caseness (i.e. symptoms indicative of likely minor psychiatric disorder) across socio- and occupational-demographic groups. Pearson's $\chi^{2}$ tests with Cramer's $V$ were also applied to compare ranks in terms of the proportion reporting high exposure to job stressors identified in the preceding interview phase. For aim 3, Pearson's correlations $(r)$ were applied to highlight the pattern of relationships between job stressor exposure and psychological distress. For $\mathrm{V}$ and $r$ analyses an effect size of $>0.30$ was applied as a practical relevance criterion, with significant findings achieving this threshold presented in italics in Table 3. Hierarchical multiple linear regression was used to explore the extent to which global job stressfulness accounted for variance in psychological distress after controlling for the influence of background demographic factors (age, gender, tenure in rural policing, rank, role). A separate regression model was constructed to examine the contribution of rural policing job stressor exposures (using the mean score from each of the job demand, isolation, and critical decision item sets) to psychological distress.

\section{Results}

Results: interviews

34 interviews were conducted, comprising 19 constables, seven sergeants and eight PCSOs. The majority of participants were male $(n=25)$, with the majority aged $40-49$ and in their current role for 10 or more years. Three high-order themes of rural policing job stressor were identified: (1) job demands, (2) isolation and (3) critical decisions, each containing multiple sub-themes (Table 1 ).

Job demands. Many interviewees reported that staff shortages enforced a requirement to juggle tasks and make decisions about which to prioritise. Officers reported being faced with a dilemma concerning "how to identify which jobs not to do, and how to justify and document the reasons for not doing them." The resultant focus on urgent tasks was perceived as making the force "largely reactive and not engaged in preventative policing" which, in turn was viewed as having a negative impact on the quality of service provided to the public: "We are not able to give a good service as there is insufficient time to dedicate to investigating crime."

The notion of the rural police officer being both a first responder and investigator - and the tension between these roles - was frequently raised: "It is the most intensely stressful way to work and sooner or later the force must realize we cannot be both an investigator and a response officer." Investigative work tended to get neglected in order to deal with additional calls for service, which led to a feeling of letting the public down: "As a rural response officer 
Theme 1: job demands

Competing demands on time

Insufficient officer headcount to meet demand

Understaffed due to backfilling

Intensive work

Tasks neglected due to workload

Understaffed due to annual leave and training

Theme 2: isolation

Backup too far away to assist when required

Worry about distance from backup

Worry about safety when working alone

Theme 3: critical decisions Make critical decisions independently

Make critical decisions quickly
Juggling everything really. . .you've got to make sure that you're keeping your victims satisfied and up to date, but also trying to manage the stuff that's coming in constantly

There's just not enough of us. On a shift, for example today, there's myself and two others at XX and a sergeant. So my colleagues in XX have got a prisoner, so that's both of them tied up, that's me now covering coast to mid-land on my own

We constantly have to backfill for response officers and assist them, but nobody comes back and assists us with ours; ours is always still waiting for us

Intensively working is everyday. The only time we get to breathe is occasionally on a night shift for an hour. Other than that we are slogged $24 / 7$

I can go for weeks without speaking to my victims; we're meant to speak to them every so many days to update them, but it just does not get done Out here there are four Response Officers per Response Section. There's always somebody generally off for annual leave or one reason or another, which generally leaves three. If you get an arrest, two of them go to custody, one stays to take evidence and take statements, no response left at all

We get sent to jobs that are probably 45 min from the nearest backup. Quite often we're routinely sent without anyone else, so they'll have to wait until we get there and then if we shout up you're talking $45 \mathrm{~min}$, potentially in a fight or protecting yourself while you're waiting for somebody else to turn up

Being a single crewed police officer in a rural patch is dangerous. My back up could be up to $20 \mathrm{~min}$ away if there is a unit available. It is something I constantly think about and causes me anxiety

For me the biggest psychological aspect, I feel a certain anxiety when I'm going to a job that I know could go horrendously wrong and I'm on my own. You think to yourself, if it goes wrong, I might not be going home today', and that's quite an impactful thing to think

If there's two of you there's someone else to talk to, someone else to bounce ideas off and make decisions. But, when you're searching for a missing person and you make decisions, you're the only person that makes those decisions. . . but then you come into work the next day and that person's jumped off the cliff, you start to doubt your initial decision Always dealing with stuff on our own and you, you know, use your decision making model and you decide what you're going to do, where you're going to go, you're constantly re-evaluating everything, as to whether you go in. When you have to deal with something straight away, whether you can afford to sit back, observe, wait for back up
Table 1. Rural policing job stressors

you are expected to respond and when not responding you have to investigate crimes. ...During busy peak demand times of the year your crime workload gets neglected, which is not fair on the victims of those crimes." Some noted that normal demand could usually be met with a full staffing compliment, yet absences arising due to annual leave or training could quickly imperil that ability. 
PIJPSM

44,1

Isolation. Interviewees identified distance from backup as "something I constantly think about and causes me anxiety," with many noting "underlying anxiety that you do not know what you're going to get sent to really and - are you going to be able to deal with that safely?" Many accounts concerned risk of harm in dealing with violent incidents with no prospect of timely backup: "Backup can be over 1 h away. We often have to get physical with suspects. Imagine going to a job that appears to be of no risk on your own that soon escalates into a violent incident and you are on your own dealing with it with no back up." Similarly, "There have been several occasions where we have been fighting with someone after being assaulted for at least 30 min whilst we wait for back up. The patch is too big and too isolated it terrifies me that one day soon someone will get hurt badly if not killed."

Critical decisions. The requirement to make critical decisions quickly and independently emerged as a key stressor. Many noted that extensive use of single-crewed patrols precluded opportunities to discuss a course of action: "if there's two of you there's someone else to bounce ideas off and make decisions", leaving the responsibility of making critical decisions independently to weigh heavily. Linked to this, some interviewees noted that staff shortages contributed to fewer opportunities to seek support for decisions: "Lack of staff in my station means I am regularly working alone. Sometimes I enjoy this; however, it can be stressful when having to make decisions".

Supervisor inaccessibility - "I only have a temporary sergeant who is acting, he is also based at a separate station over 15 miles away" - and unavailability was lamented for the barrier it presented to the seeking of a second opinion for critical decisions, with unavailability attributed to supervisors' work demands such as "acting inspector duties, which means we very rarely have direct supervision and rely on response supervisors who are not always available or acting/unqualified supervisors themselves."

\section{Results: survey}

A total of 263 survey responses were submitted, with 229 cases available for analysis after data cleansing. Socio- and occupational-demographic characteristics of the sample are shown in Table 2. The overall response rate was $20 \%$, with variance between ranks: PCSO, $35 \%$; constable, $17 \%$; sergeant, $24 \% .27 \%$ of respondents were female, representing a slightly lower proportion than present in the force's rural policing population (35\%). Overall, $30 \%$ of respondents reported high job stressfulness (very or extremely stressful), with significant differences evident by rank: the proportion of PCSOs reporting high job stressfulness was less than half that among constables and sergeants. The overall prevalence of psychological distress caseness (symptoms indicative of likely minor psychiatric disorder) was $44 \%$, with no significant differences between ranks.

The proportion of respondents reporting high exposure to each context-specific job stressor, stratified by rank, is shown in Table 3. For demand and critical decision stressors, significant differences in exposure rates were observed across ranks, with PCSOs mostly reporting lower exposure than constables and sergeants, while isolation-related stressor exposure rates were similar across ranks. Correlations between frequency of job stressor exposure and psychological distress are also shown in Table 3. Among PCSOs, significant associations of medium effect size were observed between psychological distress and seven (of 11) job stressors across the demand, isolation, and critical decision stressor themes, with higher levels of psychological distress associated with higher stressor exposures. For constables, four job stressors across the demand and isolation themes met this threshold, while among sergeants significant associations of medium effect size were observed for stressors within the job demand theme only.

In linear regression analyses with psychological distress as the criterion variable the covariates (age, gender, tenure in rural policing, rank, role) explained $4 \%$ of the variance (model 1), although this was not statistically significant, $F(5,227)=1.86, p=0.10$. 


\begin{tabular}{|c|c|c|c|c|c|c|}
\hline & $N(\%)$ & $\begin{array}{c}\text { Job stressfulness } \\
\text { High (very or } \\
\text { extremely stressful) \% }\end{array}$ & $\chi^{2}, V$ & $\begin{array}{c}\text { Psychological } \\
\text { distress } \\
\text { Caseness (GHQ- } \\
12 \geq 4) \% \\
\end{array}$ & $\chi^{2}, V$ & $\begin{array}{l}\text { English rural } \\
\text { policing }\end{array}$ \\
\hline Overall & & 30 & & 44 & & \\
\hline Gender & & & $3.76,0.13$ & & $0.18,0.03$ & \\
\hline Male & $166(73)$ & 34 & & 46 & & 57 \\
\hline Female & $63(27)$ & 21 & & 42 & & \\
\hline Age & & & $9.12,0.20$ & & $5.17,0.15$ & \\
\hline $\begin{array}{l}\leq 29 \\
30-39\end{array}$ & $\begin{array}{r}20(8) \\
63(28)\end{array}$ & $\begin{array}{l}20 \\
27\end{array}$ & & $\begin{array}{l}65 \\
41\end{array}$ & & \\
\hline $40-49$ & $82(36)$ & 31 & & 47 & & \\
\hline $50-59$ & $55(24)$ & 42 & & 38 & & \\
\hline$\geq 60$ & $9(4)$ & 0 & & 33 & & \\
\hline Rank & & & $8.16^{*}, 0.19$ & & $3.16,0.12$ & \\
\hline $\begin{array}{l}\text { Police community } \\
\text { support officer }\end{array}$ & $50(22)$ & 14 & & 43 & & \\
\hline Constable & $142(62)$ & 34 & & 48 & & \\
\hline Sergeant & 37 (16) & 38 & & 38 & & \\
\hline Years in rural policing & & & $6.29,0.16$ & & $4.59,0.14$ & \\
\hline$\leq 4$ & $88(38)$ & 35 & & 44 & & \\
\hline$\overline{5}-9$ & $43(19)$ & 20 & & 32 & & \\
\hline 10-14 & $72(31)$ & 26 & & 52 & & \\
\hline 15-19 & $21(9)$ & 36 & & 46 & & \\
\hline$\geq 20$ & $5(3)$ & 60 & & 40 & & \\
\hline Role & & & $1.68,0.08$ & & $5.88,0.16$ & \\
\hline Local investigation & $11(5)$ & 33 & & 42 & & \\
\hline $\begin{array}{l}\text { Neighbourhood } \\
\text { policing }\end{array}$ & $78(34)$ & 27 & & 46 & & \\
\hline Response & $129(56)$ & 33 & & 47 & & Table 2. \\
\hline Other & $11(5)$ & 18 & & 9 & & Participant \\
\hline Note(s): $* p<0.05$ & & & & & & characteristics (survey) \\
\hline
\end{tabular}

The addition of global job stressfulness (Model 2) explained 24\% extra variance as compared to model $1\left(R^{2}=0.28\right)$ and was statistically significant $F(6,226)=14.77, p<0.001$. In a separate model with rural policing job stressors as predictors, model 1 was identical to that shown above. The addition of rural policing job stressors (Model 2) explained 16\% extra variance as compared to model $1\left(R^{2}=0.20\right)$ and was statistically significant $F(8,224)=6.89$, $p<0.001$. In the final model, the significant predictors were job demands $(\beta=0.27, p<0.001)$ and isolation stressors $(\beta=0.19, p<0.01)$.

\section{Discussion}

This study identified three job stressor themes in English rural policing: job demands, isolation and critical decisions. For demand and critical decision stressors differences in exposure rates were observed by rank, with PCSOs reporting lower exposure than constables and sergeants. Higher levels of psychological distress were associated with higher stressor exposure across all three job stressor themes for PCSOs and constables and within the job demand theme for sergeants. $44 \%$ of respondents reported symptoms of psychological distress indicative of likely minor psychiatric disorder. Though lower than the $52 \%$ prevalence rate observed in contemporaneous British policing research (Houdmont and Randall, 2016), this rate remains high compared to the general UK workforce (32\%) (Goodwin 


\section{PIJPSM 44,1}

Table 3.

Job stressor exposure and associations with psychological distress
Job stressor high exposure

All PCSO Constable Sergeant

( $\%$ often, very often, always exposed)

$\begin{array}{lllll}85 & 54(-0.06) & 92\left(0.35^{* *}\right) & 97\left(0.33^{*}\right) & 47.19^{* * *}, 0.45 \\ 85 & 70\left(0.43^{* *}\right) & 89\left(0.27^{* *}\right) & 87(0.28) & 10.90^{* *}, 0.22 \\ & & & & \\ 65 & 46\left(0.39^{* *}\right) & 70\left(0.20^{*}\right) & 73(0.06) & 10.37^{* *}, 0.21 \\ 64 & 34(0.08) & 71\left(0.24^{* *}\right) & 76\left(0.40^{*}\right) & 24.77^{* * *}, 0.33 \\ 61 & 34(0.27) & 69\left(0.41^{* *}\right) & 65(0.26) & 19.33^{* * *}, 0.29 \\ 59 & 42\left(0.38^{* *}\right) & 66(0.15) & 51(0.05) & 9.85^{* *}, 0.21\end{array}$

$\begin{array}{rlrrr}78 & 74\left(0.40^{* *}\right) & 80\left(0.30^{* *}\right) & 76(0.21) & 1.02,0.07 \\ 75 & 72\left(0.33^{*}\right) & 78\left(0.30^{* *}\right) & 68(0.17) & 2.10,0.10 \\ 72 & 60\left(0.44^{* *}\right) & 75\left(0.26^{* *}\right) & 78(-0.04) & 4.82,0.15\end{array}$

$77 \quad 48(0.28) \quad 82(0.19 *) \quad 95(-0.03) \quad 32.40^{* * *}, 0.38$

$7240(0.33 *) \quad 80(0.23 * *) \quad 84(-0.12) \quad 32.81 * * *, 0.38$
Job demands

Competing demands on time

Insufficient officer headcount to meet

demand

Understaffed due to backfilling

Intensive work

Tasks neglected due to workload

Understaffed due to annual leave and

training

\section{Isolation}

Backup too far away to assist when required

Worry about distance from backup

Worry about safety when working alone

Critical decisions

Make critical decisions independently

Make critical decisions quickly

Note(s): $* p<0.05, * * p<0.01, * * * p<0.001$

Correlation coefficients in parenthesis. Coefficients $\geq 0.3$ practical relevance threshold in italic

et al., 2013) and double that observed in the adult population (19-20\%) (Scottish Government, 2019). The observed rate is also considerably higher than observed in policing in other national contexts. For instance, a comparatively low rate of $17 \%$ was observed among Finnish police officers (Leino et al., 2011), which might be explained in terms of Finland's strong social cohesiveness and sense of fairness, in addition to heavy investment in a comprehensive social security system (Vuorensyrjä and Mälkiä, 2011). In the current study slightly more than one in three constables and sergeants $(34 \%$ and $38 \%$ ) and a lower proportion of PCSOs (14\%), reported high global job stressfulness. Rates for sworn police officers were lower than the $44 \%$ observed in a contemporaneous nationwide policing study involving constables and sergeants (Elliott-Davies, 2018), yet more than double that observed in the general working population (Health and Safety Executive, 2012; Scottish Government, 2018). Further research is warranted to establish whether rates of psychological distress and job stressfulness observed in the current study generalize to rural policing nationally.

The three job stressor themes identified in this study are consistent with the wider policing literature with regard to the identification of job demands as a key stressor across roles and contexts (e.g. Allisey et al., 2014). Findings concerning isolation were consistent with the international rural policing literature; for instance, Oliver and Meier (2004) similarly identified issues such as distance from backup as problematic in North American rural policing. The final job stressor theme - a requirement to make critical decisions quickly and independently - appears to be under-explored as a source of stress in policing, with recent research highlighting its importance: in a US study "making critical on-the-spot decisions" was reported by police officers as the single most stressful of 44 potential stressors (Padalli, 2020). Taken together, these findings suggest that further research is warranted to explore interventions for rural police teams to address competing and excessive demands associated with the requirement to fulfil multiple policing functions, concerns linked to isolation and vulnerability and provision of support for decision-making. 
The mental health of PCSOs has only recently become a focus in police stress research. One previous study explored psychological distress among 12 PCSOs in an urban UK police force (Shafiq et al., 2016), while our study is the first to focus on those serving rural communities. We found the prevalence of psychological distress in PCSOs consistent with that of constables and sergeants. However, the proportion of PCSOs reporting high job stressfulness was less than half that of constables and sergeants. One explanation for this apparent disconnect is that in response to a global measure of job stressfulness respondents typically consider job demands (Houdmont et al., 2019), which in the current study were considerably lower for PCSOs than the other groups. This study has shown that job stressors for PCSOs in rural policing teams are to some extent distinct from those experienced by constables and sergeants, highlighting the necessity for a strand of PCSO-specific research - in parallel to that for officers - to identify aspects of work that may benefit from modification to stimulate occupational health gains.

Despite its strengths, there are some limitations of this study that must be taken into account when interpreting the findings. Officers on sick leave and those who had resigned may have been affected by job stressors more than those in the study population, raising the possibility of an under-estimation of the prevalence of the study variables and associations between these. Cross-sectional research designs make an important contribution to the exploration of new ideas owing to efficiencies in time and funding requirements and an ability to demonstrate the existence of relationships between variables which itself is a crucial first step towards establishing a causal link (Spector, 2019). Nevertheless, they are limited by an inability to detect causal relations between variables. We suggest a causal order of the study variables whereby exposure to job stressors leads to psychological distress, yet it is possible that associations could result from reverse causality or reciprocal relationships. Future studies involving retrospective reports (to help establish the temporal order of variables), alternative sources of data (e.g. clinical interview data concerning psychological distress) or longitudinal or diary designs could help to definitively establish the causal direction of these relationships.

Self-report offers a pragmatic and efficient means of data collection in job stress research yet raises the possibility of common method variance involving artificially inflated correlations between variables. However, there is growing evidence to suggest that the influence of common method variance may not be as high as commonly believed (Spector and Nixon, 2019). Moreover, for some of our variables (e.g. frequency of exposure to job stressors) no valid alternative assessment methods exist, while internal states such as psychological distress may be best mapped by means of reports provided by those involved in these experiences.

Exploratory studies concerning neglected topics are typically restricted in scale. This ensures efficient use of resources at a point in the unfolding research process when questions remain as to whether the new line of research is likely to bear fruit. In accordance with this approach, the current preliminary exploration of job stress in rural policing in England involved officers drawn from a single force. Large-scale studies are now required involving officers from rural policing teams across multiple forces to establish the extent to which the job stressor and psychological distress profiles identified herein generalize to rural policing nationally. To limit the time required for survey completion we did not collect data on the full range of factors that might influence perceptions of job stressors and mental well-being. Future studies should seek to take account of a broad set of work-related characteristics including commute time, shift length, rotations and other possible contributory factors in order to achieve a full understanding of rural police stress.

In conclusion, the current study has offered an initial insight into the nature of job stressors experienced by rural policing teams in England and links between stressor exposure and mental health. In this way, it provides a foundation for future research that
English rural policing 
PIJPSM

44,1

60 recognizes context- and role-specific job stressors in rural policing and seeks to inform targeted and tailored actions to protect and promote the mental health of those involved in the policing of rural communities.

\section{References}

Aalto, A.-M., Elovainio, M., Kivimaki, M., Uutela, A. and Pirkola, S. (2012), "The beck depression inventory and general health questionnaires as measures of depression in the general population: a validation study using the composite international diagnostic interview as the gold standard", Psychiatry Research, Vol. 197 Nos 1-2, pp. 163-171.

Allisey, A., Noblet, A., LaMontage, A. and Houdmont, J. (2014), "Testing a model of officer intentions to quit: the mediating effects of job stress and job satisfaction”, Criminal Justice and Behavior, Vol. 41 No. 6, pp. 751-771.

Bakker, A. and Demerouti, E. (2017), "Job demands-resources theory: taking stock and looking forward", Journal of Occupational Health Psychology, Vol. 22 No. 3, pp. 273-285.

Boag-Munroe, F. (2017), "National detectives survey 2017 headline report", available at: http://www. polfed.org/documents/National $\% 20$ Detectives $\% 20$ Survey $\% 20$ Headline $\% 20$ Statistics $\%$ 202017\% 20-\%20report\%20-\%2006-10-17\%20v1.0.pdf (accessed 1 February 2020).

Braun, V. and Clarke, V. (2006), "Using thematic analysis in psychology", Qualitative Research in Psychology, Vol. 3 No. 2, pp. 77-101.

Buttle, J., Fowler, C. and Williams, M. (2010), "The impact of rural policing on the private lives of New Zealand police officers", International Journal of Police Science and Management, Vol. 12 No. 4, pp. 596-606.

Cartwright, A. and Roach, J. (2020), "The wellbeing of UK police: a study of recorded absences from work of UK police employees due to psychological illness and stress using Freedom of Information Act data", Policing: A Journal of Policy and Practice, Advance Online Publication.

Demou, E., Hale, H. and Hunt, K. (2020), "Understanding the mental health and wellbeing needs of police officers and staff in Scotland", Police Practice and Research, Advance Online Publication.

Department for Environment, Food, and Rural Affairs (2014), "Local authority districts ranked by rural and hub town (rural-related) populations 2011, using 2011 Rural Urban Classification", available at: https:/www.gov.uk/government/statistics/2011-rural-urban-classification-of-local-authority-andother-higher-level-geographies-for-statistical-purposes (accessed 1 February 2020).

Department for Environment, Food, and Rural Affairs (2018), "Official statistics: rural population 2014/15", available at: https://www.gov.uk/government/publications/rural-population-andmigration/rural-population-201415 (accessed 1 February 2020).

Elliott-Davies, M. (2018), "Police federation of England and Wales demand, capacity, and welfare survey 2018: headline statistics", available at: https:/www.polfed.org/media/14060/ demandcapacityandwelfaresurveyheadlinestatistics2018-06-02-19-v1.pdf (accessed 1 February 2020).

Goldberg, D. and Williams, P. (1988), User's Guide to the General Health Questionnaire, NFER-Nelson, Windsor.

Goodwin, L., Ben-Zion, I., Fear, N., Hotopf, M., Stansfeld, S. and Wessely, S. (2013), "Are reports of psychological stress higher in occupational studies? A systematic review across occupational and population based studies”, PLoS ONE, Vol. 8 No. 11, e78693.

Health and Safety Executive (2012), "Psychosocial working conditions in britain in 2010", available at: http://www.hse.gov.uk/statistics/pdf/pwc2010.pdf (accessed 1 February 2020).

Health and Safety Executive (n.d.), "What are the management Standards?”, available at: https://www. hse.gov.uk/stress/standards/index.htm (accessed 1 February 2020).

Home Office Statistics (2019), "Police workforce, England and Wales, 31 march 2019", available at: https://assets.publishing.service.gov.uk/government/uploads/system/uploads/attachment_data/ file/831726/police-workforce-mar19-hosb1119.pdf (accessed 24 September 2020). 
Houdmont, J. (2013), "UK police custody officers' psychosocial hazard exposures and burnout", Policing: An International Journal of Police Strategies and Management, Vol. 36 No. 3, pp. 620-635.

Houdmont, J. and Randall, R. (2016), "Working hours and common mental disorders in English police officers", Occupational Medicine, Vol. 66 No. 9, pp. 713-718.

Houdmont, J., Randall, R. and Kerr, R. (2012), "Organisational psychosocial hazard exposures in UK policing: management standards indicator tool reference values”, Policing: An International Journal of Police Strategies and Management, Vol. 35 No. 1, pp. 182-197.

Houdmont, J., Jachens, L., Randall, R., Hopson, S., Nuttall, S. and Pamia, S. (2019), "What does a singleitem measure of job stressfulness assess?", International Journal of Environmental Research and Public Health, Vol. 16 No. 9, p. 1480.

Huey, L. and Ricciardelli, R. (2015), “This isn't what I signed up for': when police officer role expectations conflict with the realities of general duty police work in remote communities", International Journal of Police Science and Management, Vol. 17 No. 3, pp. 194-203.

Huey, L. and Ricciardelli, R. (2017), "Policing 'domestic disturbances' in small towns and rural communities: implications for officer and victim safety”, Canadian Review of Sociology, Vol. 54 No. 2, pp. 198-215.

Hurrell, A.-K., Draycott, S. and Andrews, L. (2018), "Secondary traumatic stress in police officers investigating childhood sexual abuse”, Policing: An International Journal, Vol. 41 No. 5, pp. 636-650.

Husain, W. (2019), "Depression, anxiety, and stress among urban and rural police officers", Journal of Police and Criminal Psychology, Vol. 35 No. 4, pp. 433-447.

Jackman, P., Clay, G., Coussens, A., Bird, M. and Henderson, H. (2020), "We are fighting a tide that keeps coming against us': a mixed method exploration of stressors in an English county police force", Police Practice and Research, Advance Online Publication.

Leino, T., Selin, R., Summala, H. and Virtanen, M. (2011), "Violence and psychological distress among police officers and security guards", Occupational Medicine, Vol. 61 No. 6, pp. 400-406.

Mawby, R. (2009), "Perceptions of police and policing in a rural county of England", International Journal of Police Science and Management, Vol. 11 No. 1, pp. 39-53.

National Farmers' Union (2017), “Combating rural crime”, available at: https://www.nfuonline.com/ nfu-online/news/nfu-reports/nfu-report-combatting-rural-crime-july-2018/ (accessed 24 September 2020).

National Police Chiefs' Council (2018), "Rural affairs strategy", available at: https:/www.npcc.police. uk/documents/crime/2018/NPCC \% 20Rural\% 20affairs \% 20Strategy \%202018\%202021.pdf (accessed 24 September 2020).

National Rural Crime Network (2015), "The true cost of crime in rural areas", available at: https:// www.nationalruralcrimenetwork.net/content/uploads/2015/09/NRCN-National-Rural-CrimeSur...pdf (accessed 24 September 2020).

Office for National Statistics (2011), “2011 rural/urban classification”, available at: https://www. ons.gov.uk/methodology/geography/geographicalproducts/ruralurbanclassifications/ 2011ruralurbanclassification (accessed 1 February 2020).

Oliver, W.M. and Meier, C. (2004), "Stress in small town and rural law enforcement: testing the assumptions", American Journal of Criminal Justice, Vol. 29 No. 1, pp. 37-57.

Padalli, K. (2020), "Sources and severity of stress in a Southwestern police department", Occupational Medicine, Vol. 70 No. 2, pp. 131-134.

Page, K. and Jacobs, S. (2011), "Surviving the shift: rural police stress and counseling services", Psychological Services, Vol. 8 No. 1, pp. 12-22.
English rural policing 
PIJPSM 44,1

Raper, M., Brough, P. and Biggs, A. (2020), "Evidence for the impact of organisational resources versus job characteristics in assessments of occupational stress over time", Applied Psychology: An International Review, Vol. 69 No. 3, pp. 715-740.

Ricciardelli, R. (2018), "Risk it out, risk it out': occupational and organizational stresses in rural policing", Police Quarterly, Vol. 21 No. 4, pp. 415-439.

Ricciardelli, R., Spencer, D. and Andres, E. (2018), "Driving as an under-acknowledged risk in rural policing", Policing: Journal of Policy Practice, Vol. 14 No. 3, pp. 657-669.

Scottish Government (2018), "The Scottish health survey 2017 edition - summary", available at: https://www.gov.scot/publications/scottish-health-survey-2017-summary-key-findings/ (accessed 1 February 2020).

Scottish Government (2019), "The Scottish health survey 2018 edition - main report”, available at: https://www.gov.scot/publications/scottish-health-survey-2018-volume-1-main-report/ (accessed 1 February 2020).

Shafiq, N., Ohlsson, I. and Mathias, P. (2016), "Predictors of punitive attitudes among police officers", Journal of Forensic Practice, Vol. 18 No. 1, pp. 76-86.

Sheard, I., Burnett, M. and St Clair-Thompson, H. (2019), "Psychological distress constructs in police with different roles", International Journal of Emergency Services, Vol. 8 No. 3, pp. 264-279.

Smith, A. (2000), "The scale of perceived occupational stress", Occupational Medicine, Vol. 50 No. 5, pp. 294-298.

Spector, P. (2019), "Do not cross me: optimizing the use of cross-sectional designs", Journal of Business and Psychology, Vol. 34 No. 2, pp. 125-137.

Spector, P. and Nixon, A. (2019), "How often do I agree: an experimental test of item format method variance in stress measures", Occupational Health Science, Vol. 3 No. 2, pp. 1-19.

Turner, T. and Jenkins, M. (2019), “Together in work, but alone at heart': insider perspectives on the mental health of British police officers", Policing, Vol. 13 No. 2, pp. 147-156.

Vuorensyrjä, M. and Mälkiä, M. (2011), "Nonlinearity of the effects of police stressors on police officer burnout”, Policing: An International Journal of Police Strategies and Management, Vol. 34 No. 3, pp. 382-402.

Wu, G. and Wen, M. (2020), "Predicting three dimensions of police officer stress: does rural or urban setting matter?", Policing: An International Journal of Police Strategies and Management, Vol. 43 No. 3, pp. 435-449.

\section{Corresponding author}

Jonathan Houdmont can be contacted at: jonathan.houdmont@nottingham.ac.uk

For instructions on how to order reprints of this article, please visit our website:

www.emeraldgrouppublishing.com/licensing/reprints.htm

Or contact us for further details: permissions@emeraldinsight.com 